Original Research

\title{
Using the RS Method to Analyse Construction Land Changes in Tongren during 2002 and 2016
}

\author{
Huaipeng Liu*, Yongxin Zhang, Xiaoping Zhang \\ School of Land and Tourism, Luoyang Normal University, Luoyang, Henan Province, China
}

Received: 7 September 2017

Accepted: 4 March 2018

\begin{abstract}
Timely and accurately obtained regional construction land information for environmental protection, ecological construction, and regional planning is important. In this study, we used Landsat7 ETM+ images acquired in 2002 and Landsat8 images acquired in 2016 as data sources, and performed maximum likelihood classification and class masking in order to extract construction land information in Tongren. The experimental results showed that the construction land of the study area was 306.07 $\mathrm{km}^{2}$ in 2002 and $675.15 \mathrm{~km}^{2}$ in 2016. This shows an increase of $369.08 \mathrm{~km}^{2}$, which marks an increase by $120.59 \%$, while the expansion ratio was quite larger. Construction land was mainly transferred from cultivated land $\left(338.65 \mathrm{~km}^{2}\right)$, and shows that large areas of cultivated land were replaced by construction land. The main reason for the construction land increase was urban expansion, and the county expansion ratio was between 3.72 and 7.92. Road construction, mining destruction, and residential expansion are additional reasons, but these have caused smaller changes to the area of construction land, with a change ratio of only 0.34 . In mountainous Karst areas, urban expansion may cause ecological problems; therefore, we should protect the natural environment and maintain the landscape in its original state so as not to cause excessive disturbance to land resources.
\end{abstract}

Keywords: China Tongren, RS method, construction land, change detection, expansion reason

\section{Introduction}

Construction land refers to basic places where people engage in all social and economic activities. It is a land designated for the building of infrastructure, and includes urban and rural land; public facilities; tourism, military, industrial, and mining land; energy, transportation, and water conservation facilities;

*e-mail: gatestudy@163.com communications; and other infrastructure [1-2]. With the rapid development of resource utilisation, urbanisation, and industrialisation, natural resources are increasingly becoming scarce, and regional construction land is expanding rapidly. Moreover, the ecological environment is threatened, and sustainable development is facing great challenges. Under the premise of meeting development needs without destroying the natural environment, the scarcity of land resources is increasingly becoming more prominent. All levels of government attach great importance to the land as the 
core of natural resources and with regard to ecological environmental protection and intensive utilisation [3-4].

Land use is closely related to the development of the social economy and ecological security; therefore, obtaining the spatial and temporal pattern of regional construction land, and the current situation, in a timely and accurate manner has an important practical significance for the comprehensive coordination and overall planning of urban and rural land use structure [5]. Remote sensing technology has become important for land use/land cover classification and change detection at global, regional, and local scales [6-11]. Landsat series satellite imaging is one of the most common data sources for construction land extraction. The methods for extracting construction land information mainly include the spectral relation threshold method [12], single index method [13-15], pixel decomposition method [1617], multi index method [18-19], classification [20], and so on. The most commonly used methods are the single index method and classification, which are easy to understand and obtain results quickly and accurately.

In Tongren, forest resources are rich and vegetation coverage abounds. This has great natural ecological advantages; however, the region is characterised by typical mountainous Karst landscape, and is also a typical representative of Southwest China, where geological disasters frequently occur. Thus human interference, including large-scale construction and land planning, should be kept to a minimum. Interest has been expressed by scholars and government leaders regarding the changes that have been made to the construction land in this region over the last 10 years. Such an assessment will help us understand how we impacted the environment in the past, and take good measures to protect it in the future. In this study, we took Landsat7 ETM+ and Landsat8 images as the data sources using a classification method in order to extract construction land information from 2002 and 2016. By statistics and analysis, we deduced construction land changes for 2002 and 2016 and provided the basic data for the planning of regional resource development and ecological and environmental protection.

\section{Materials and Methods}

\section{Study Area Situation}

Tongren is located in the northeast region of the Guizhou Province in China (Fig. 1), and lies in the three provinces of Guizhou, Hunan, and Chongqing in the Wuling mountainous hinterland. It is in the slope zone of the Yunnan and Guizhou Plateau to Xiangxi hills, with a land area of $18,000 \mathrm{~km}^{2}$. It has a typical karst landscape, and the ecological environment is very fragile.

The city's administrative area is a subtropical monsoon and humid climate zone, with annual sunshine of 1,044.7-1,266.2 h, annual average temperature

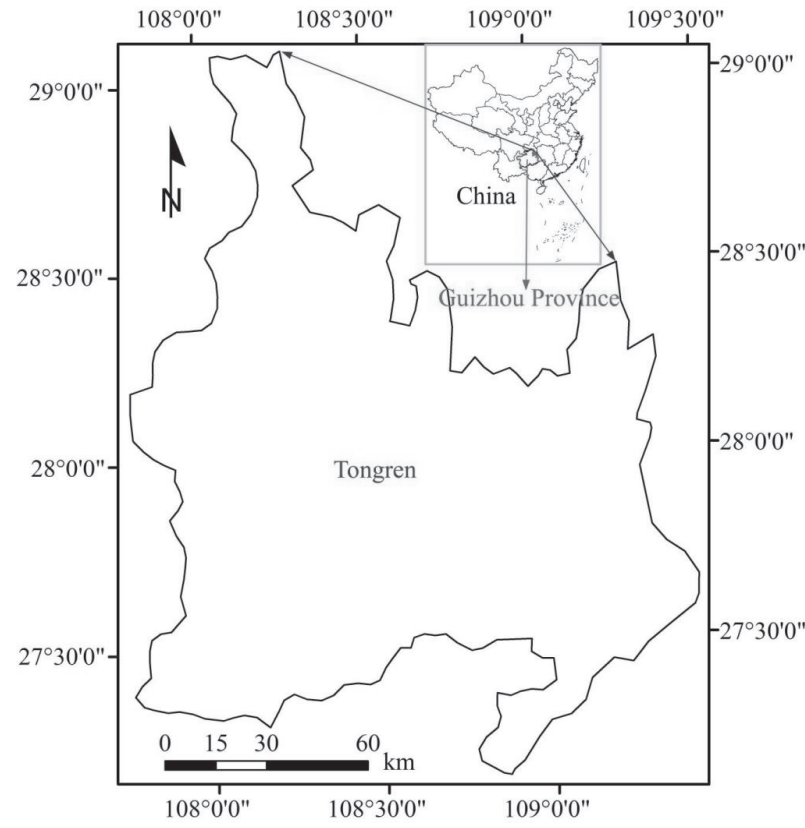

Fig. 1. Map of study area.

of $13.5-17.6^{\circ} \mathrm{C}$, average annual precipitation of 1,110-1,410 mm, and frost-free periods lasting 275 to 317 days, with rich heat, light, and abundant precipitation. There are two national nature reserves, three national scenic areas, three provincial scenic spots, one national mine park (karst), and one national geological park. Fanjing Mountain is another area, under Tongren's jurisdiction, and a member of the United Nations Human and Biosphere Reserve Network. It is also a national nature reserve and a famous Buddhist mountain in China, with a regional forest coverage rate of above $95 \%$, which contains negative oxygen ions per cubic centimetre, and up to $6 \sim 12$ million. The giant salamander (Davidia involucrata Baill) and many other rare and endangered animals and plants live and thrive here. Without a doubt, there is high ecological and cultural value in these well-known mountains and rivers of China [21].

\section{Data Sources}

Free research data was downloaded from the United States Geological Survey (USGS) website, where recent images from Landsat8, imaged on 29 August 2016, were obtained. The panchromatic and multispectral image resolutions were $15 \mathrm{~m}$ and $30 \mathrm{~m}$, respectively, and the track numbers of the two scene images were 126/40 and 126/41, respectively. Since image capturing is affected by cloud cover, it was difficult to find images of Tongren with less than $20 \%$ cloud coverage. We queried earlier dates and found that the Landsat7 ETM+ images (track number was also 126/40 and 126/41) captured in 31 August 2002 had no cloud coverage. Therefore, we downloaded these two scenes of remotely sensed images. At last, we had different image sources over 
Table 1. Number of pixels in the training and accuracy of verification samples.

\begin{tabular}{|c|c|c|c|c|c|c|}
\hline \multirow{2}{*}{ Ground type } & \multicolumn{2}{|c|}{ Typical images } & \multicolumn{2}{|c|}{ Training sample pixels } & \multicolumn{2}{|c|}{ Precision validation pixels } \\
\hline & Landsat7 ETM+ & Landsat8 & Landsat7 ETM+ & Landsat8 & Landsat7 ETM+ & Landsat 8 \\
\hline Forest land & & & 1,580 & 1,525 & 3,026 & 3,043 \\
\hline Cultivated land & & & 1,440 & 1,532 & 3,036 & 3,012 \\
\hline $\begin{array}{c}\text { Construction } \\
\text { land }\end{array}$ & & & 1,504 & 1,576 & 3,047 & 3,030 \\
\hline Water & & & 1,446 & 1,599 & 3,019 & 3,050 \\
\hline
\end{tabular}

a 14-year period, and these would be used for construction land information extraction. Auxiliary data included vectors of the Tongren prefecture, Guizhou Province, and China administrative boundaries.

\section{Image Pre-Processing}

Before extracting the construction land information, Landsat7 ETM+ and Landsat8 images were synthesised by multispectral bands, respectively. Next, the multispectral and panchromatic images were fused, the single-scene fused image was cut out, and finally the two scene images of Landsat7 ETM+ and Landsat8 were combined in a mosaic. Finally, image data with $15 \mathrm{~m}$ spatial resolution at different times and from different data sources were obtained and the final captured image was processed at the latitude and longitude ranges of $107^{\circ} 44^{\prime} 15.93^{\prime \prime}-109^{\circ} 29^{\prime} 33.78^{\prime \prime} \mathrm{E}$ and $27^{\circ} 06^{\prime} 27.95^{\prime} "-29^{\circ} 04^{\prime} 4.67^{\prime \prime} \mathrm{N}$, respectively.

\section{Image Classification}

In order to analyse the transfer between different types of land in Landsat7 ETM+ and Landsat8 images, the types of land have to be subdivided into forest, cultivated, and construction lands and water. In order to obtain a high-quality and representative sample data, we used field survey combined with image analysis. The samples were collected by Google Earth (the distinction of 4 ground classes was based on the typical images in Table 1). By using the region of interest (ROI) tool of ENVI 4.5, we collected enough samples for the 4 types of land shown in the images. Moreover, the sample data were balanced in the entire study area. We divide the collected samples into training and validation samples, and used stratified random sampling in order to select a certain number of pixels for these two categories. The numbers of training and validation samples for Landsat7 ETM+ and Landsat8 are listed in Table 1.

We used Maximum likelihood classification for Landsat7 ETM+ (bands 1, 2, 3, 4, 5, and 7) and Landsat8 (bands 2, 3, 4, 5, 6, and 7) image classification, respectively. Finally, validation samples were used in order to verify classification accuracy, and classification was stopped when the overall accuracy was over $85 \%$; otherwise, the training sample was re-selected.

\section{Change Monitoring}

After obtaining the classification map of the two images, we used Landsat8 classification map minus the Landsat7 ETM+ classification map, and obtained the spatial transfer information of the 4 ground classes. Subsequently, we masked forest land, cultivated land and water, from the Landsat7 ETM+ and Landsat8 classification map, respectively. Additionally, we analysed the growth of construction land in each county in Tongren, and used the perimeter-area fractal dimension (PAFRAC) in order to measure the boundary shape complexity of each county [22].

\section{Results and Discussion}

\section{Classification Results Validation}

The confusion matrix of Landsat7 ETM+ and Landsat8 classification results is shown in Tables 2 and 3. 
Table 2. Confusion matrix for classification results of Landsat7 ETM+.

\begin{tabular}{|c|c|c|c|c|c|c|}
\hline Ground type & Forest land & Cultivated land & Construction land & Water & Row total & User accuracy \% \\
\hline Forest land & 2,753 & 395 & 55 & 52 & 3,255 & 84.58 \\
\hline Cultivated land & 248 & 2,604 & 33 & 5 & 2,890 & 90.10 \\
\hline Construction land & 11 & 28 & 2,936 & 34 & 3,009 & 97.57 \\
\hline Water & 14 & 9 & 23 & 2,928 & 2,974 & 98.45 \\
\hline Column total & 3,026 & 3,036 & 3,047 & 3,019 & 12,128 & \\
\hline Producer accuracy \% & 90.98 & 85.77 & 96.36 & 96.99 & & \\
\hline
\end{tabular}

Overall accuracy $=(11221 / 12128)=92.5214 \%$; Kappa coefficient $=0.9003$

Table 3. Confusion matrix for classification results of Landsat8.

\begin{tabular}{|c|c|c|c|c|c|c|}
\hline Ground type & Forest land & Cultivated land & Construction land & Water & Row total & User accuracy \% \\
\hline Forest land & 2,841 & 362 & 39 & 55 & 3,297 & 86.17 \\
\hline Cultivated land & 172 & 2,572 & 43 & 4 & 2,791 & 92.15 \\
\hline Construction land & 4 & 78 & 2,947 & 62 & 3,091 & 95.34 \\
\hline Water & 26 & 0 & 1 & 2,929 & 2,956 & 99.09 \\
\hline Column total & 3,043 & 3,012 & 3,030 & 3,050 & 12,135 & \\
\hline Producer accuracy \% & 93.36 & 85.39 & 97.26 & 96.03 & & \\
\hline
\end{tabular}

Overall accuracy $=(11289 / 12135)=93.0284 \%$; Kappa coefficient $=0.9070$

From Table 2 we can see that the overall accuracy was 92.5214\% (Kappa coefficient of 0.9003), and that the producer accuracy of land classification ranged from $85.77 \%$ (cultivated land) to $96.99 \%$ (water), while user accuracy ranged from $84.58 \%$ (forest land) to $98.45 \%$ (water).

Table 3 shows that the overall accuracy was 93.0284\% (Kappa coefficient of 0.9070), and the producer accuracy of land classification ranged from $85.39 \%$ (cultivated land) to $97.26 \%$ (construction land), while user accuracy ranged from $86.17 \%$ (forest land) to 99.09\% (water).

From Tables 2 and 3 we can see that the overall accuracy was high, and that the producer and user accuracy of each classes were also high. The classification results meet the needs of the study.

\section{Types of Land Extraction Analysis}

In 2002 and 2016 the Tongren areas of forest, cultivated, and construction lands and water that were extracted are shown in Table 4. The types of land extraction results are shown in Fig. 2 a) and b).

As can be seen from Table 4, the total land area of Tongren is approximately $18,028.56 \mathrm{~km}^{2}$. By using Landsat7 ETM+ in 2002 the areas of forest, cultivated, and construction lands and water were $11,407.26 \mathrm{~km}^{2}$, $6,124.80 \mathrm{~km}^{2}, 306.07 \mathrm{~km}^{2}$, and $190.43 \mathrm{~km}^{2}$, respectively. Accordingly, the proportion of the 4 types of land accounted for the total area was $63.27 \%$, 33.97\%, $1.70 \%$, and $1.06 \%$, respectively. By using Landsat 8 in 2016, the areas of forest, cultivated, and construction lands and water were $11,374.18 \mathrm{~km}^{2}, 5,758.67 \mathrm{~km}^{2}$,

Table 4. Types of land area statistics for 2002 and 2016.

\begin{tabular}{|c|c|c|c|c|}
\hline \multirow{2}{*}{ Ground object type } & \multicolumn{2}{|c|}{2002} & \multicolumn{2}{c|}{2016} \\
\cline { 2 - 5 } & Area $\left(\mathrm{km}^{2}\right)$ & Percentage of the total area (\%) & Area $\left(\mathrm{km}^{2}\right)$ & Percentage of the total area (\%) \\
\hline Forest land & $11,407.26$ & 63.27 & $11,374.18$ & 63.09 \\
\hline Cultivated land & $6,124.80$ & 33.97 & $5,758.67$ & 31.94 \\
\hline Construction land & 306.07 & 1.70 & 675.15 & 3.74 \\
\hline Water & 190.43 & 1.06 & 220.56 & 1.22 \\
\hline Total area & $18,028.56$ & 100.00 & $18,028.56$ & 100.00 \\
\hline
\end{tabular}



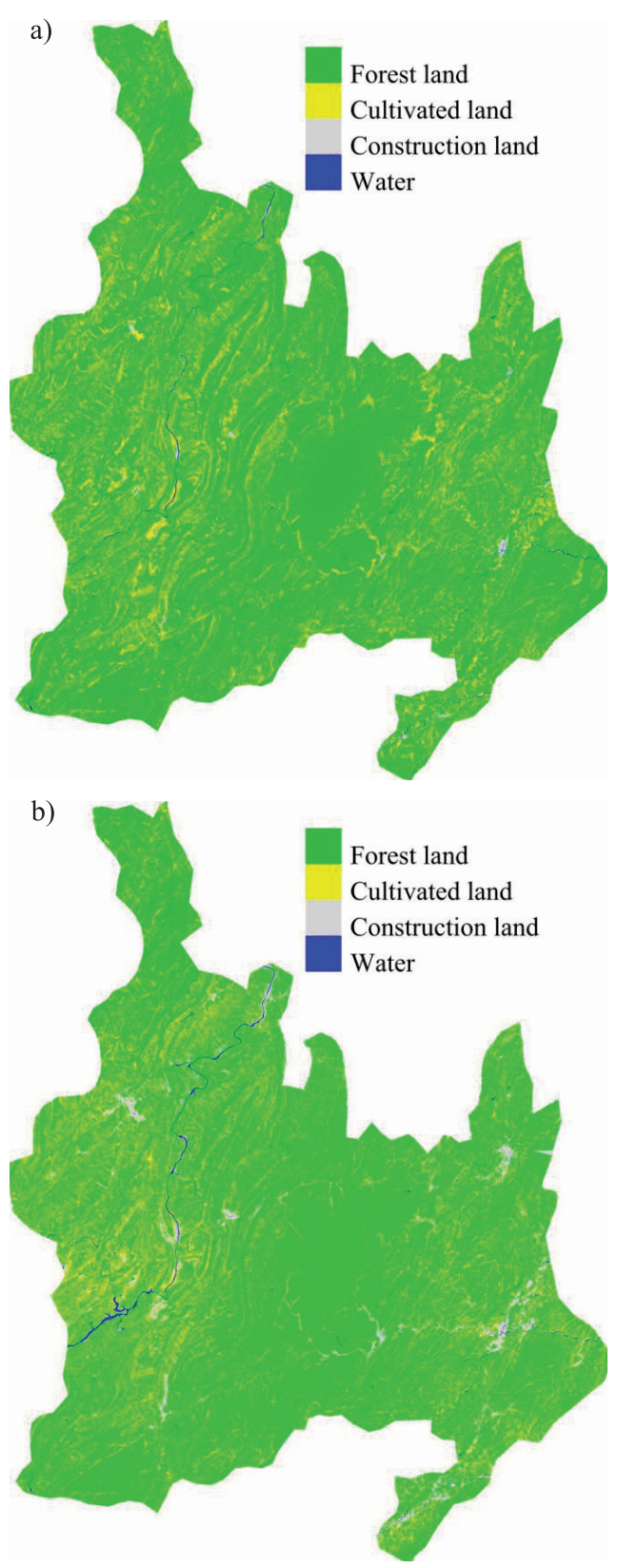

Fig. 2. Types of land distribution map in 2002 and 2016: a) Types of land distribution in 2002, b) Types of land distribution in 2016.
$675.15 \mathrm{~km}^{2}$, and $220.56 \mathrm{~km}^{2}$, respectively. Accordingly, the proportion of the 4 types of land accounted for total areas of $63.09 \%, 31.94 \%, 3.74 \%$, and $1.22 \%$, respectively. In 2002 and 2016, the proportion of forest land and cultivated land was larger, while others accounted for a smaller proportion.

As can be seen in Fig. 2, in 2002 and 2016 the land types of cultivated land, construction land, and water changed noticeably. This demonstrates that the local ecological environment has been disturbed greatly by human activity.

\section{Change Analysis}

The transfer matrix of the 4 types of land areas extracted in 2002 and 2016 is presented in Table 5.

As can be seen from Table 5, from 2002 to 2016 forest land was mainly converted to cultivated land, construction land, and water. However, the area of this class that was transferred to construction land, was larger $\left(66.86 \mathrm{~km}^{2}\right)$ than the others. Cultivated land and water were converted to construction land, which was also larger than others $\left(338.65 \mathrm{~km}^{2}\right.$ and $13.78 \mathrm{~km}^{2}$, respectively). The area of construction land was converted to other types of land that was smaller (less than $34.86 \mathrm{~km}^{2}$ ). In the past 14 years before 2016, the area of forest land and cultivated land decreased by $33.08 \mathrm{~km}^{2}$ and $366.13 \mathrm{~km}^{2}$, respectively. The area of construction land and water increased by $369.08 \mathrm{~km}^{2}$ and $30.13 \mathrm{~km}^{2}$, respectively. Construction land was mainly transferred from cultivated land $\left(338.65 \mathrm{~km}^{2}\right)$, followed by forest land $\left(66.86 \mathrm{~km}^{2}\right)$, and showed that large areas of cultivated land and forest land were replaced by construction land. In 2016, construction land area increased by $369.08 \mathrm{~km}^{2}$, which amounts to an increase of $120.59 \%$ in comparison to 2002.

\section{Construction Land Change Analysis}

To further analyse construction land changes in Tongren, we masked forest land, cultivated land, and water from the classification map, and only

Table 5. Transfer matrix of 4 types of land in 2002 and 2016.

\begin{tabular}{|c|c|c|c|c|c|c|}
\hline & \multicolumn{7}{|c|}{$2002\left(\mathrm{~km}^{2}\right)$} \\
\hline & & Forest land & Cultivated land & Construction land & Water & Row total \\
\cline { 2 - 8 } & Forest land & $11,289.67$ & 40.53 & 34.86 & 9.12 & $11,374.18$ \\
\cline { 2 - 8 } $2016\left(\mathrm{~km}^{2}\right)$ & Cultivated land & 16.76 & $5,730.97$ & 10.21 & 0.73 & $5,758.67$ \\
\cline { 2 - 8 } & Construction land & 66.86 & 338.65 & 255.86 & 13.78 & 675.15 \\
\cline { 2 - 8 } & Water & 33.97 & 14.65 & 5.14 & 166.8 & 220.56 \\
\cline { 2 - 8 } & Class total & $11,407.26$ & $6,124.8$ & 306.07 & 190.43 & \\
\cline { 2 - 8 } & This class changes & 117.59 & 393.83 & 50.21 & 23.63 & \\
\cline { 2 - 8 } & Image Difference & -33.08 & -366.13 & 369.08 & 30.13 & \\
\hline
\end{tabular}


a)

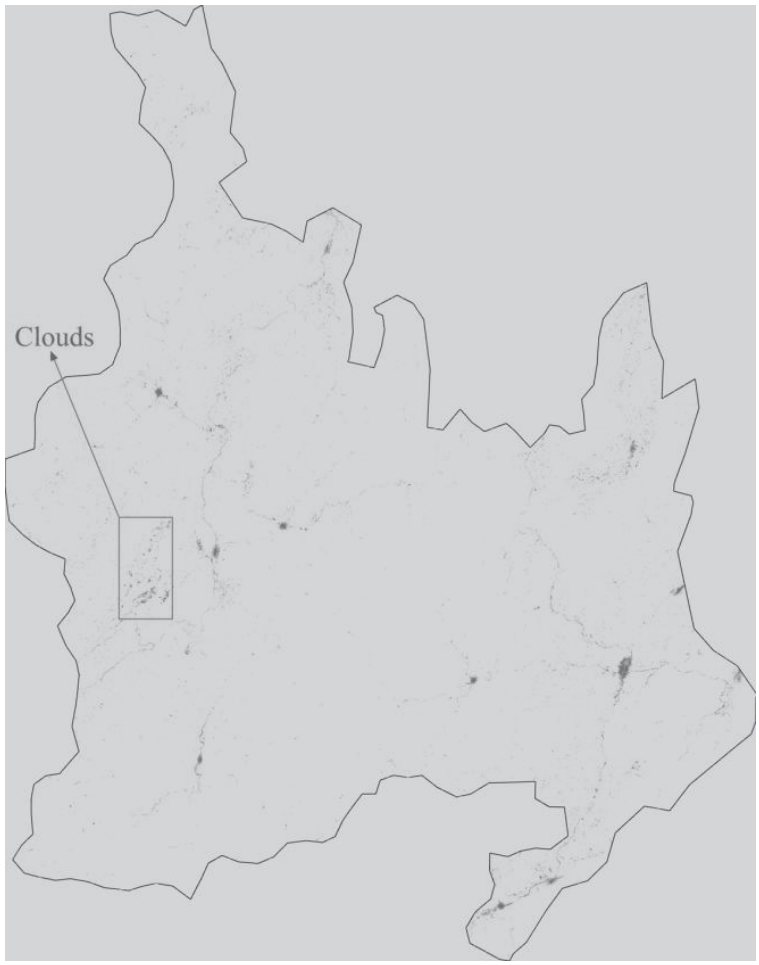

b)

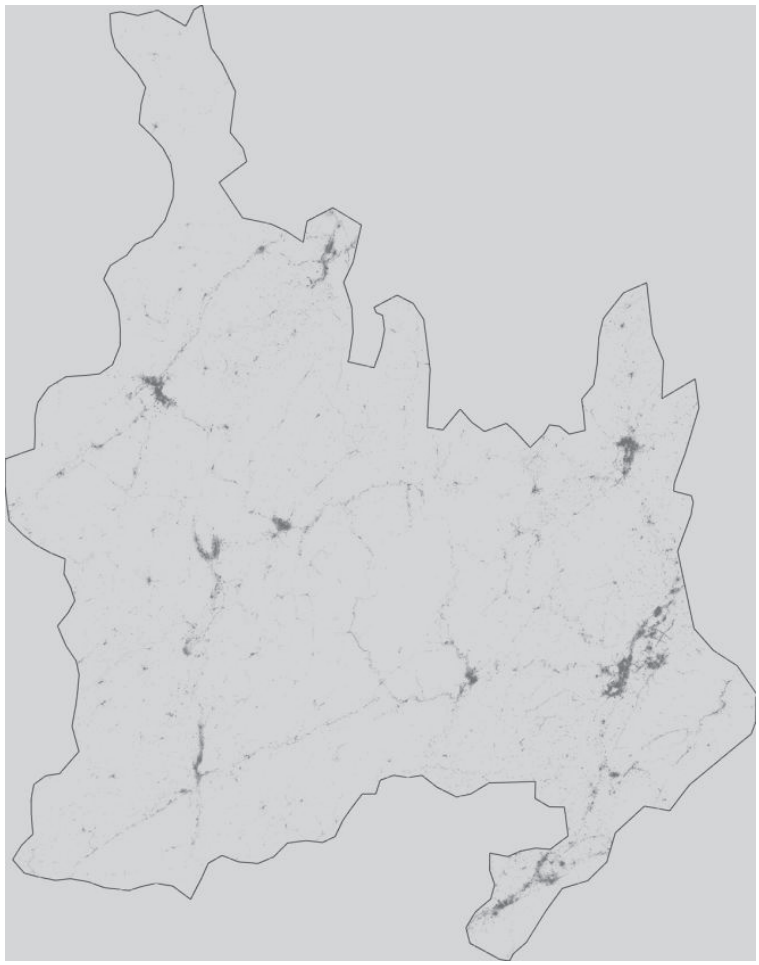

Fig. 3. Construction land distribution map in 2002 and 2016: a) Construction land distribution in 2002, b) Construction land distribution in 2016 .

retained the construction land information in the map. The construction land distribution maps in 2002 and 2016 are shown in Fig. 3.

In Fig. 3a), construction land is represented by the purple section. In 2002, on the left side of the image, little clouds were mistakenly extracted as construction

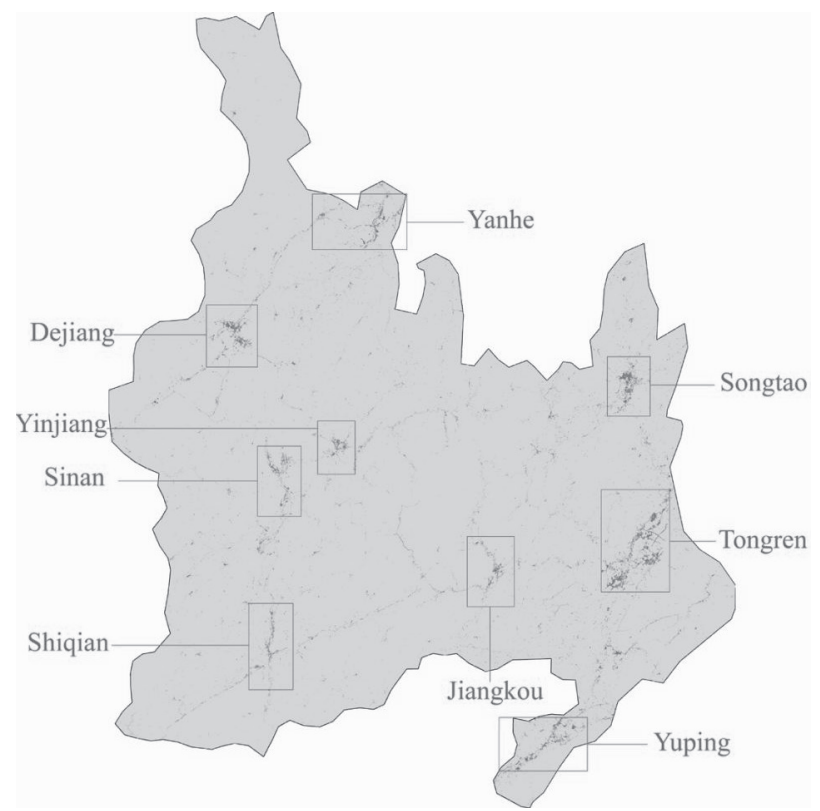

Fig. 4. Newly added construction land distribution.

land; therefore, this part was extracted with a slight inaccuracy. However, the extraction of other parts was accurate. As can be seen from Fig. 3, in 2002 and 2016 the construction land was mainly distributed in the city, and very little distributed in other places, which could have been roads, villages, mines, and so on. In 2002 the distribution of construction land was sparse; however, in 2016, the construction land distribution was relatively concentrated, and its range expanded significantly.

By using a later time phase construction land distribution map and by subtracting the previous time phase construction land distribution map, we obtained the spatial distribution of the newly added construction land distribution map, which is shown in Fig. 4.

As can be seen from Fig. 4, the newly added construction land is mainly distributed around the city, such as in the counties of Dejiang, Yinjiang, Sinan, Shiqian, Yanhe, Songtao, Jiangkou, and Yuping, and the city of Tongren.

We calculated construction land changes and PAFRAC in different counties and the city of Tongren, the results are presented in Table 6.

From Table 6 we can see that in 2002 all cities in the area were small. In 2016, all cities have a large area. Yanhe County had the largest expansion ratio (7.92) and Yinjiang County had the smallest (3.72); the expansion ratios of other cities were between these two counties. The construction land of all cities had the greatest expansion in 2016 in comparison to 2002. However, the construction land of others places changed less (change ratio of 0.34) in comparison to cities. These places were road construction, mining destruction, and residential extension.

We assume that in plain areas, urban boundaries may be simpler, as the PAFRAC value approaches 1.0; in the mountainous region the land becomes hard to use, 
Table 6. Specific construction land changes.

\begin{tabular}{|c|c|c|c|c|c|c|c|}
\hline \multirow{2}{*}{ Classes } & \multirow{2}{*}{$\begin{array}{l}\text { Specific } \\
\text { category }\end{array}$} & \multicolumn{2}{|c|}{2002} & \multicolumn{2}{|c|}{2016} & \multirow{2}{*}{$\begin{array}{l}\text { Expanded area } \\
\qquad\left(\mathrm{km}^{2}\right)\end{array}$} & \multirow{2}{*}{$\begin{array}{c}\text { Area } \\
\text { expansion ratio }\end{array}$} \\
\hline & & Area $\left(\mathrm{km}^{2}\right)$ & PAFRAC & Area $\left(\mathrm{km}^{2}\right)$ & PAFRAC & & \\
\hline \multirow{9}{*}{$\begin{array}{l}\text { County } \\
\text { and city }\end{array}$} & Dejiang & 4.75 & 1.3167 & 32.73 & 1.3798 & 27.97 & 5.89 \\
\hline & Yinjiang & 2.99 & 1.3440 & 14.12 & 1.3936 & 11.12 & 3.72 \\
\hline & Sinan & 4.96 & 1.3338 & 35.01 & 1.4015 & 30.05 & 6.06 \\
\hline & Shiqian & 3.60 & 1.3511 & 24.38 & 1.3898 & 20.78 & 5.77 \\
\hline & Yanhe & 3.70 & 1.3259 & 32.96 & 1.3846 & 29.26 & 7.92 \\
\hline & Songtao & 4.28 & 1.2916 & 34.92 & 1.3803 & 30.64 & 7.16 \\
\hline & Jiangkou & 3.71 & 1.3302 & 22.42 & 1.3995 & 18.71 & 5.05 \\
\hline & Yuping & 8.21 & 1.3405 & 43.09 & 1.3752 & 34.89 & 4.25 \\
\hline & Tongren & 15.59 & 1.3284 & 94.83 & 1.3823 & 79.23 & 5.08 \\
\hline Others & $\begin{array}{l}\text { Residential land, road, } \\
\text { mining, etc. }\end{array}$ & 254.28 & -- & 340.70 & -- & 86.42 & 0.34 \\
\hline
\end{tabular}

and urban boundaries may exhibit complex shapes when the PAFRAC value becomes larger than 1.0 and keeps increasing with the expansion of the city [22]. In 2002 Shiqian County had the largest PAFRAC (1.3511), while Songtao County has the lowest PAFRAC (1.2916). Other PAFRAC values between the two counties had little

a)

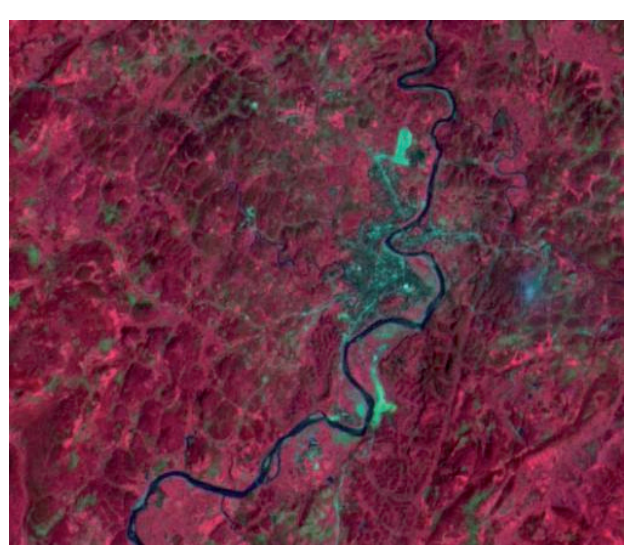

b)

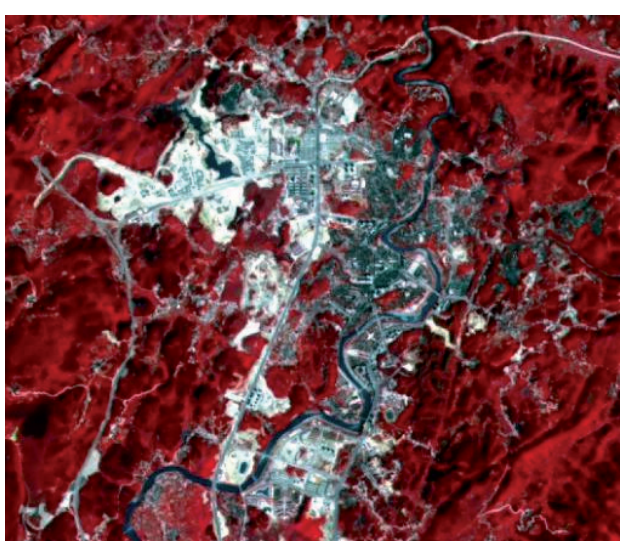

Fig. 5. Construction land distribution in Songtao County during 2002 and 2016: a) Landsat7 ETM+ in 2002, b) Landsat8 in 2016. difference and showed that the boundary complexity of these counties is similar. In 2016, Sinan County had the largest PAFRAC (1.4015), while Yuping County had the lowest PAFRAC (1.3752). Other PAFRAC values between the two counties had little difference. Compared with the previous period, the PAFRAC value of all cities increased, which shows that the boundary of all cities became more complex. This indicates that urban expansion in the mountainous karst area was greatly influenced by topography. We observed the construction land and main traffic lines and water systems in the study area, and found that the cities are expanding along the main roads and river systems, unlike the concentric ring expansion in the plain area, which shows that land use in this region is extremely difficult.

With the acceleration of the urbanisation process, vegetation was destroyed due to urban expansion in areas that were originally covered by it. The land gradually transformed into urban construction land. We consider Songtao County as such an example cut out of the county images for Landsat7 ETM+ in 2002 and Landsat8 in 2016 (Fig. 5).

As can be seen from Fig. 5, in 2002 the Songtao County area was very small, and with good vegetation cover around the city. However, by 2016 there had been large changes, and the bare ground area of the city expanded several times, while a large part of the vegetation disappeared.

\section{Consequences of Expansion}

After 2000 China compiled a new urban development plan. Chinese cities were constantly expanding as large populations rushed in. Consequently, housing prices soared and urban expansion accelerated. Currently, we believe that China's continuous urban expansion is due to a background of times factors, development cost factors, and system defect factors [23]. Under 


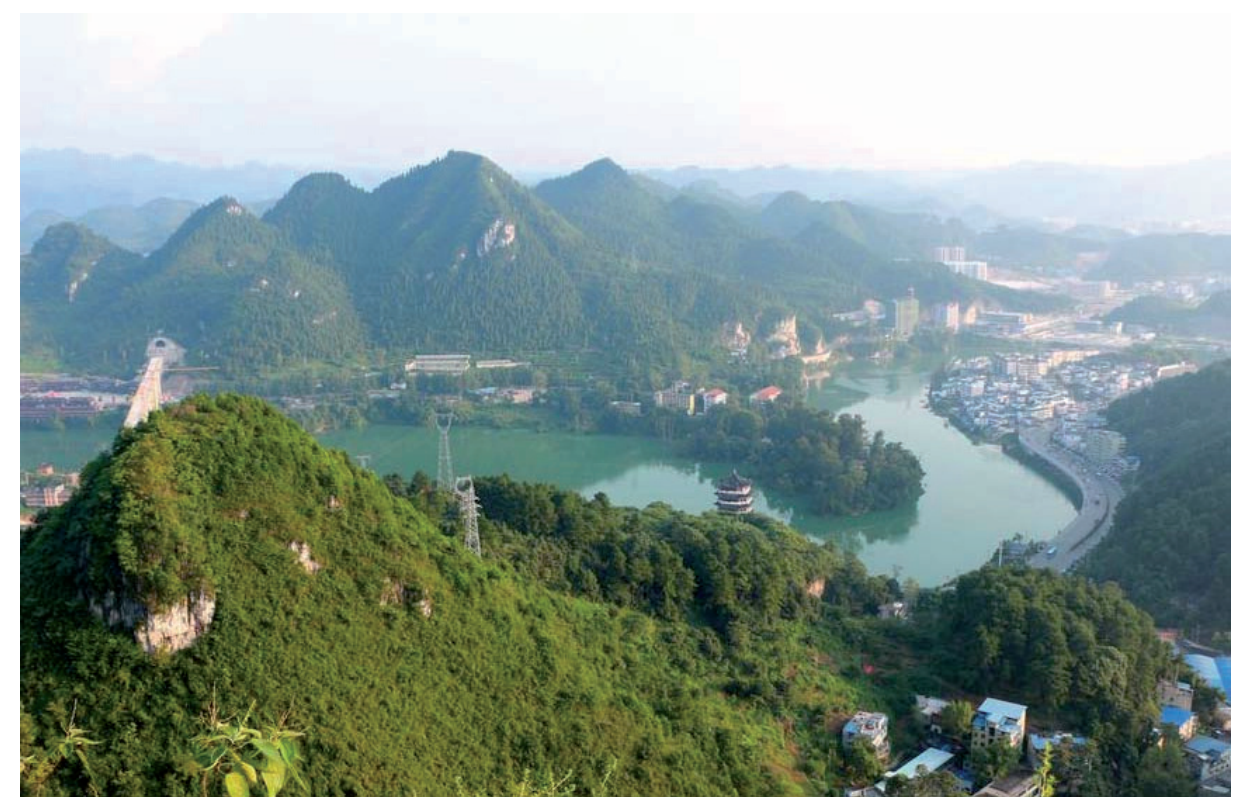

Fig. 6. Photo from a hill of Tongren.

the influence of these factors, the geologically fragile karst area also participated in the big wave of urban expansion. Tongren is one of the most developed areas on the karst landform. Karst covers approximately $61 \%$ of the total area, and the mountainous area accounts for approximately $67.8 \%$ of the total. The mountain slopes are more than 15 degrees and are difficult to use [24]. The relatively flat land area only accounts for $11.76 \%$ of the total area, and its distribution is more dispersed [25]. Presently, $31.84 \%$ of the relative flat land is used as construction land, therefore the supply of urban land in this area is very grim and the economic cost of urbanisation is enormous. The continued expansion of the city will reduce the amount of high-quality land and cause serious waste of land resources. Moreover, landslides may easily occur due to soil erosion, land rocky desertification, and ground collapse problems. We captured a photograph in Tongren's hill, and it is displayed in Fig. 6.

We can see that there are many hills on the periphery of the city. Due to the limitation imposed by the hills, the expansion of the city will be blocked. If the city continues to expand, it will not only pay a huge financial cost, but will also destroy the mountains and exert unpredictable impact to the ecological environment, which will also have detrimental financial consequences. We can also see that the mountains are green, the water is very clear, and the scenery here is beautiful. We extracted the vegetation coverage in the study area and the results showed that $95 \%$ of the earth's surface is covered by vegetation. There are thousands of large rivers, and the negative oxygen ion is very rich. Therefore, this is a suitable location for a summer resort or health spa, but not large-scale urban development. In view of the above analysis, it follows that we should keep this area in its original state or exploit its ecological advantages in order to develop a tourism industry instead of simply constructing buildings and expanding the city for the purpose of economic development.

By recognising the dangers of large-scale development in the Yangtze Economic Zone (mostly made from karst landform), Chairman $\mathrm{Xi}$ stated in January 2016 that, in this region, we should "take great protection for the environment, and not engage in largescale development." By this statement, Chairman Xi elevated awareness with regard to ecological restoration and the environment [26]. In view of our national leaders' attention to the ecological environment in southern China, the development of the karst area will be reversed in order to ensure that the ecological environment of the region recovers and that it remains protected thereafter.

\section{Conclusions}

In this study, Landsat7 ETM+ images from 2002 and Landsat8 images from 2016 were taken as data sources. By using Maximum likelihood classification the two images were divided into 4 land types, respectively, and by analysing the construction land transfer between different ground classes, the experimental results showed that:

1) The construction land of the study area was 306.07 $\mathrm{km}^{2}$ (accounting for $1.70 \%$ of the total area) and $675.15 \mathrm{~km}^{2}$ (accounting for 3.74\%) in 2002 and 2016 , respectively. In comparison to 2002, the area expanded by $369.08 \mathrm{~km}^{2}$ in 2016 , which amounts to $120.59 \%$. Therefore, the expansion ratio was quite a bit larger.

2) The construction land was mainly transferred from cultivated land $\left(338.65 \mathrm{~km}^{2}\right)$, followed by forest land 
$\left(66.86 \mathrm{~km}^{2}\right)$. This shows that in Tongren large areas of cultivated land and forest land were replaced by construction land.

3) The main reason for the increase of construction land was urban expansion. The expansion ratios of cities were between 3.72 and 7.92. Other reasons were road construction, mining destruction, residential expansion, and so on. However, the aforementioned factors caused the construction land area to have smaller changes, with a change ratio of only 0.34 .

Land resources in the karst area are more precious, and excessive urban expansion will occupy highquality cultivated land, which will force farmers to reclaim land in the mountains and lead to soil erosion, rocky desertification, landslides, and animal and plant population reduction. These can potentially cause great pressure on the ecological environment. Thus, in the process of land use in the karst region, attention should be paid to land intensive use and ecological and environment protection. Therefore, it is preferable to develop a tourism industry rather than the urban environment for the purpose of economic development.

In the southern region of China, obtaining satellite images that are not covered by clouds is particularly difficult. In this study, with regard to previous image selection, we found that most images were obscured by clouds and could not be used to extract the construction land. Finally, in this study, we chose the 31 August 2002 image of Landsat7 ETM+ that includes only a few clouds. By using this image, the extracted construction land was not so precise; therefore, the aim of future work will be to improve the accuracy of construction land extraction from the 2002 images.

\section{Acknowledgements}

This work was supported by the National Nature Science Foundation of China (grant Nos. 61502219 and 41501466) and the International Science and Technology Cooperation Program of China (grant No. 2016YFE0104600). We want to extend our gratitude to the editors and the anonymous reviewers.

\section{Conflict of Interest}

The authors declare no conflict of interest.

\section{References}

1. HU W., YANG Y.H., DUAN Z.L. On Intelligent Extraction of Construction Land Based On High-Resolution Satellite Image. Geology of Anhui, 3, 210, 2014.

2. SUN F., XU S.W., WU X.C., XU S.H. Application of high reliability and automatic construction land change detection to land supervision. Remote Sensing for Land and Resources, 2, 131, 2015.
3. KONG W., GUO J., HAO O.M. Study on Land Intensive Use Response on Economic Development and Regional Differentiated Control of Constructed Land. China Population, Resources And Environment, 24, 100, 2014.

4. LIU Y., LI X. Study on sustainable development strategy of construction land in China. Economic Review, 9, 24, 2013.

5. RAO P., WANG J.L., WANG Y. Extraction of information on construction land based on multi-feature decision tree classification. Transactions of the Chinese Society of Agricultural Engineering, 30, 233, 2014.

6. TOWNSHEND J.R.G., CHRISTOPHER O.J. Towards operational monitoring of terrestrial systems by moderate-resolution remote sensing. Remote Sensing of Environment, 83, 351, 2002.

7. LUNETTA R.S., LYON J.G (EDS.). Geospatial data accuracy assessment. Las Vegas: Environmental Protection Agency, 87, 2003.

8. JENSEN, J.R. Introductory Digital Image Processing: A Remote Sensing Perspective: Third Edition. New Jersey: Prentice Hall, Inc, 2005.

9. GAO Z.Q., NING J.C., GAO W. Response of land surface temperature to coastal land use/cover change by remote sensing. Transactions of the CSAE, 25, 274, 2009.

10. SCHNEIDER A. Monitoring land cover change in urban and peri-urban areas using dense time stacks of Landsat satellite data and a data mining approach. Remote Sensing of Environment, 12, 689, 2012.

11. HU S.G., WANG L. Automated urban land-use classification with remote sensing. International Journal of Remote Sensing, 34, 790, 2013.

12. YANG C.J., ZHOU C.H. Extracting Residential Areas on the TM Imagery. Journal of Remote Sensing, 4, 146, 2000.

13. CHA Y., NI S.X., YANG S. An Effective Approach to Automatically Extract Urban Land-use from TM Imagery. Journal of Remote Sensing, 7, 37, 2003.

14. ZHA Y., GAO J., NI S. Use of normalized difference builtup index in automatically mapping urban areas from TM imagery. International Journal of Remote Sensing, 24, 583, 2003.

15. YANG Z.X., HE X.F. Automatic extraction of urban land-use information from remote sensing images based on improved NDBI method. Journal of Hohai University(Natural Sciences), 38, 181, 2010.

16. POWELL R.L., ROBERTS D.A., DENNISON P.E., HESS L.L. Sub-pixel mapping of urban land cover using multiple endmember spectral mixture analysis: manaus, brazil. Remote Sensing of Environment, 106 (2), 253, 2007.

17. WENG F.Q., PU R.L. Mapping and assessing of urban impervious areas using multiple endmember spectral mixture analysis: A case study in the city of Tampa, Florida. Geocarto International, 28, 594, 2013.

18. XU H.Q. Fast information extraction urban built-up land based on the annalysis of spectral signature and normalized difference index. Geographical Research, 24, 311, 2005.

19. YANG Y.L., TANG Y., HE Z.W., FENG J., WANG L. Identification and extraction of urban construction land information by index image - a case study of Yueyang City. Science of Surveying and Mapping, 36, 208, 2011.

20. RAO P., WANG J., WANG Y. Extraction of information on construction land based on multi-feature decision tree classification. Transactions of the Chinese Society of Agricultural Engineering, 30, 233, 2014. 
21. http://www.trs.gov.cn/news/2014414/n22.html

22. ZHANG Y.S., ODEH I.O.A., RAMADAN E. Assessment of land surface temperature in relation to landscape metrics and fractional vegetation cover in an urban/periurban region using Landsat data. International Journal for Remote Sensing, 34, 168, 2013.

23. CHEN Y.C. Study on the Reasons and Policies Towards the Rapid Expansion of Large Cities. City Planning Review, 27, 33, 2003.
24. DENG X.H., BI K. Analysison the Karst Topographic Distributionin Guizhou Province. Guizhou Geology, 21, 191, 2004

25. ZHOU X.F., ZHOU Y.Z. Urban Spatial Structure of Karst City:A Case Study of Guizhou Province. Tropical Geography, 28, 212, 2008.

26. https://wallstreetcn.com/articles/228401 